\title{
Hyponatremic Coma after Bowel Preparation
}

\author{
João Costelha ${ }^{1}$, Rita Dias ${ }^{2}$, Carla Teixeira ${ }^{3}$, Irene Aragão ${ }^{3}$ \\ ${ }^{1}$ Serviço de Medicina 2, Unidade Local de Saúde do Alto Minho, Viana do Castelo, Portugal \\ ${ }^{2}$ Serviço de Medicina, Centro Hospitalar e Universitário do Porto, Porto, Portugal \\ ${ }^{3}$ Unidade de Cuidados Intensivos Polivalente - Centro Hospitalar e Universitário do Porto, Porto, Portugal
}

Received: 17/07/2019

Accepted: 26/07/2019

Published: 26/08/2019

How to cite this article: Costelha J, Dias R, Teixeira C, Aragão I. Hyponatremic coma after bowel preparation. EJCRIM 2019;6: doi:10.12890/2019_001217.

Conflicts of Interests: The Authors declare that there are no competing interest

This article is licensed under a Commons Attribution Non-Commercial 4.0 License

\begin{abstract}
Introduction: Colonoscopy is a useful tool in modern medicine and is increasingly employed for both diagnostic and treatment purposes. However, bowel preparations can cause electrolyte imbalance, with the risk apparently related to the type of bowel cleansing solution used, the age of the patient and their comorbidities. Symptomatic hyponatremia, especially coma, is a rare complication of oral bowel preparation for colonoscopy and is thought to result from excessive antidiuretic hormone secretion.

Case description: The authors report the case of a 48-year-old man who developed symptomatic hyponatremia (coma) after bowel preparation with sodium picosulfate/magnesium oxide/citric acid prior to a colonoscopy. The patient was admitted to an intensive care unit where other causes of coma were excluded. The symptoms of hyponatremia rapidly resolved after sodium level correction with intravenous administration of hypertonic saline.

Discussion: Hyponatremic coma is an uncommon but serious complication of colonoscopy bowel preparation. Patients at risk ( $>65$ years old, chronic kidney disease, heart failure, history of electrolyte problems, or taking thiazide diuretics, angiotensin-converting-enzyme inhibitors or antidepressants) should be closely monitored during bowel cleansing and macrogol-based solutions should preferably be used.
\end{abstract}

\section{LEARNING POINTS}

- The association between coma and hyponatremia should be kept in mind when patients undergo bowel preparation, especially if they have chronic kidney disease, heart failure, a history of electrolyte problems or are taking diuretics or antidepressants.

- Patients should be closely monitored (and their metabolic profile checked before bowel cleansing) and a low threshold maintained for investigation and treatment initiation in case of symptom development.

- Medications with the potential to cause fluid and electrolytes disturbances such as diuretics and antidepressants should be stopped or reduced in dose while the patient is undergoing bowel preparation.

\section{KEYWORDS}

Hyponatremia, coma, bowel preparation

\section{INTRODUCTION}

Colonoscopy is a common procedure used for both diagnostic and therapeutic purposes in daily clinical settings and has a low risk of serious associated complications ${ }^{[1]}$. However, bowel preparations can cause electrolyte imbalance such as hyponatremia which can result in seizures, loss of consciousness, neurological symptoms and eventually coma ${ }^{[2]}$. The risk of electrolyte imbalance seems to be related to the type of bowel cleansing solution used, the age of the patient and their comorbidities ${ }^{[3]}$. 


\section{CASE DESCRIPTION}

A 48-year-old man, with a history of depression medicated with mirtazapine $30 \mathrm{mg}$ (once daily) and bupropion $300 \mathrm{mg}$ (once daily), who also recently took various herbal products for weight loss, was transferred to the emergency room from a private clinic due to sudden coma. He had been awaiting a diagnostic colonoscopy after taking a bowel preparation containing sodium picosulfate/magnesium oxide/citric acid when he became aggressive and then entered an altered state of consciousness first with shaking and then with no reactivity.

In the emergency room as the patient fluctuated between periods of agitation and prostration, orotracheal intubation was performed and he was transferred to an intensive care unit. Blood tests showed severe hyponatremia $(110 \mathrm{mmol} / \mathrm{l})$, mild hypokalemia $(3.1 \mathrm{mEq} / \mathrm{l})$ and decreased serum osmolality (230 mOsm/kg) (Table 1).

The patient did not have a history of seizures or alcohol consumption. The electrocardiogram was normal, and brain CT and MRI showed no signs of bleeding or acute brain injury. The patient's neurological symptoms were therefore considered to be related to bowel preparationinduced severe acute hyponatremia. He was treated with a slow intravenous infusion of hypertonic saline $(3 \% \mathrm{NaCl})$.

The patient was extubated within 48 hours following progressive neurological improvement. Complete neurological recovery and normalization of serum sodium levels were achieved on the seventh day of hospitalization (Fig. 1).

\begin{tabular}{|c|c|c|}
\hline Parameter & Value & Reference values \\
\hline \multicolumn{3}{|l|}{ Gasometry } \\
\hline$p H$ & 7.38 & $7.35-7.45$ \\
\hline $\mathrm{pO}_{2}$ & $87 \mathrm{mmHg}$ & $80-100 \mathrm{mmHg}$ \\
\hline $\mathrm{SatO}_{2}$ & $96 \%$ & $\geq 94 \%$ \\
\hline $\mathrm{pCO}_{2}$ & $36 \mathrm{mmHg}$ & $35-45 \mathrm{mmHg}$ \\
\hline $\mathrm{HCO}_{3}^{-}$ & $24 \mathrm{mmHg}$ & $22-28 \mathrm{mEq} / \mathrm{l}$ \\
\hline \multicolumn{3}{|l|}{ Blood Analysis } \\
\hline Haemoglobin & $15.9 \mathrm{~g} / \mathrm{dl}$ & $12-16 \mathrm{~g} / \mathrm{dl}$ \\
\hline Platelets & $349,000 / \mathrm{mm}^{3}$ & $150-400,000 / \mathrm{mm}^{3}$ \\
\hline Leucocytes & $9,670 / \mathrm{mm}^{3}$ & $3,600-11,000 / \mathrm{mm}^{3}$ \\
\hline Neutrophils & $7,398 / \mathrm{mm}^{3}$ & $1,500-8,000 / \mathrm{mm}^{3}$ \\
\hline C-reactive protein & $0.4 \mathrm{mg} / \mathrm{dl}$ & $<0.51 \mathrm{mg} / \mathrm{dl}$ \\
\hline Glycaemia & $105 \mathrm{mg} / \mathrm{dl}$ & $70-110 \mathrm{mg} / \mathrm{dl}$ \\
\hline Urea & $43 \mathrm{mg} / \mathrm{dl}$ & $17-43 \mathrm{mg} / \mathrm{dl}$ \\
\hline Creatinine & $1.02 \mathrm{mg} / \mathrm{dl}$ & $0.8-1.3 \mathrm{mg} / \mathrm{dl}$ \\
\hline Sodium & $110 \mathrm{mg} / \mathrm{dl}$ & $135-145 \mathrm{mEq} / \mathrm{l}$ \\
\hline Potassium & $3.1 \mathrm{mg} / \mathrm{dl}$ & 3.5-5.1 mEq/l \\
\hline Serum osmolality & $230 \mathrm{mOsm} / \mathrm{kg}$ & $280-300 \mathrm{mOsm} / \mathrm{kg}$ \\
\hline $\begin{array}{l}\text { Thyroid-stimulating } \\
\text { hormone }\end{array}$ & $1.06 \mu \mathrm{U} / \mathrm{ml}$ & $0.46-4.68 \mu \mathrm{U} / \mathrm{ml}$ \\
\hline $\begin{array}{l}\text { Aspartate } \\
\text { aminotransferase }\end{array}$ & $28 \mathrm{IU} / \mathrm{I}$ & 8-35 IU/I \\
\hline $\begin{array}{l}\text { Alanine } \\
\text { aminotransferase }\end{array}$ & $24 I U / I$ & $10-35 \mathrm{IU} / \mathrm{I}$ \\
\hline Myoglobin & $105 \mathrm{ng} / \mathrm{ml}$ & $1-147 \mathrm{ng} / \mathrm{ml}$ \\
\hline Troponin I & $0.04 \mathrm{ng} / \mathrm{ml}$ & $0.00-0.10 \mathrm{ng} / \mathrm{ml}$ \\
\hline
\end{tabular}

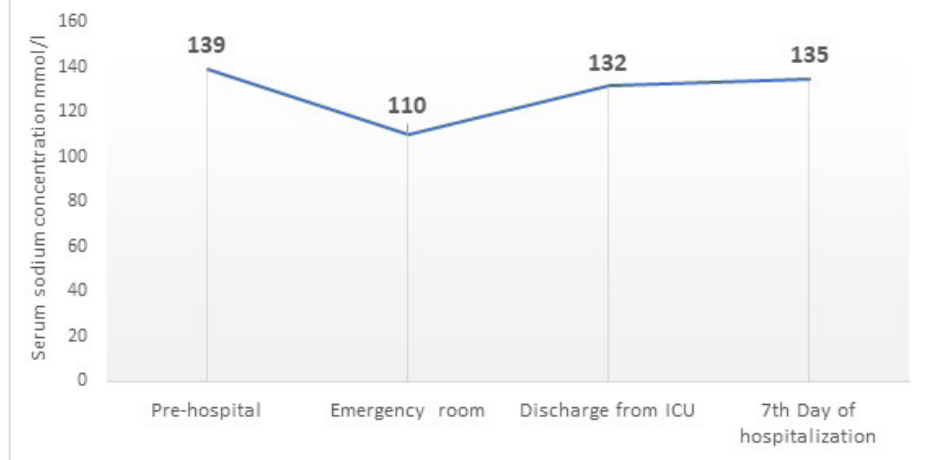

Figure 1. Evolution of patient's sodium concentration

Table 1. Analysis of patient data collected in the emergency room

\section{DISCUSSION}

Hyponatremia, essentially a disorder of water balance, is the most common electrolyte abnormality in clinical practice and has a reported incidence of $15-30 \%{ }^{[4]}$. Clinical manifestations directly attributable to hyponatremia depend on its duration and severity. They are primarily neurological, with symptoms ranging from subtle confusion, gait disturbances and attention deficit in chronic cases to seizures, coma and 
obtundation in acute hyponatremia. Hyponatremia is often multifactorial, and can have multiple aetiologies in an individual patient, which can sometimes present a diagnostic and management dilemma ${ }^{[5]}$.

Bowel preparation agents are generally regarded as safe and are well tolerated if appropriately prescribed and preparation instructions are correctly followed. However, some gastrointestinal (GI) and non-GI related adverse events are associated with their use. Gl complications include nausea, vomiting, abdominal distension and ileus. Other complications include electrolyte abnormalities including hyponatremia, seizures, encephalopathy, exacerbation of congestive heart failure and pancreatitis ${ }^{[1]}$.

Bowel regimens may cause hyponatremia through several overlapping mechanisms. One is the production of osmotic diarrhoea, causing volume depletion and stimulation of $\mathrm{ADH}$ secretion, resulting in free water retention causing hyponatremia. Another potential mechanism, as seen in our patient, is inappropriate antidiuretic hormone secretion (SIADH), which occurs if ADH secretion is not suppressed when plasma sodium concentration falls below the osmotic threshold. SIADH can be secondary to a variety of problems, including ingestion of some drugs such as antidepressants ${ }^{[5]}$.

Bowel preparation-induced coma is uncommon. The few cases reported in the literature describe patients aged 64-80 years who were taking thiazide diuretics and beta blockers; one patient had a history of gastrectomy ${ }^{[2]}$. Hyponatremic coma should be treated with slow intravenous infusion of hypertonic saline aiming to increase the sodium level at a rate of $0.5 \mathrm{mmol} / \mathrm{l} / \mathrm{h}$, while not exceeding $12 \mathrm{mmol} / \mathrm{l}$ in the first 24 hours or $18 \mathrm{mmol} / \mathrm{l}$ in the second 24 hours to avoid osmotic demyelination and brain oedema.

In conclusion, our report highlights the importance of the patient's medical history when a bowel preparation solution is being chosen (macrogol solutions should be used in individuals at risk). Moreover, if a patient presents with neurological symptoms after taking such a solution, serum electrolytes should be evaluated and treatment started immediately.

\section{REFERENCES}

1. Ehrenpreis ED, Tun NN, Melitas D. Acute hyponatremia induced by bowel preparations for colonoscopy: identification of patients at risk. Drug Des Dev Deliv J $2018 ; 1(1): 104$.

2. Costa J, Soares J. Symptomatic hyponatremia after bowel preparation. Acta Med Port 2017;30(11):824-826.

3. Saltzman JR, Cash BD, Pasha SF, Early DS, Muthusamy VR, Khashab MA, et al. Bowel preparation before colonoscopy. Gastrointest Endosc 2015;81:781-794.

4. WindpessI M, Schwarz C, Wallner M. "Bowel prep hyponatremia" - a state of acute water intoxication facilitated by low dietary solute intake: case report and literature review. BMC Nephrol 2017;18:54.

5. Samad N, Fraser I. Severe symptomatic hyponatremia associated with the use of polyethylene glycol-based bowel preparation. Endocrinol Diabetes Metab Case Rep 2017; Feb 23 pii: 16-0119. 
European Journal

of Case Reports in

Internal Medicine 